\title{
Correction to: Research to Examine Behavioral Responses to Automated Vehicles
}

Johanna Zmud, Felipe Dias, Patricia Lavieri, Chandra Bhat, Ram Pendyala, Yoram Shiftan, Maren Outwater and Barbara Lenz

\section{Correction to:}

Chapter "Research to Examine Behavioral Responses

to Automated Vehicles" in: G. Meyer and

S. Beiker (eds.), Road Vehicle Automation 5, Lecture Notes

in Mobility, https://doi.org/10.1007/978-3-319-94896-6_5

The original version of the book was inadvertently published with misspelt co-author name "Felipe Diaz" which has been now corrected to read as "Felipe Dias" in chapter "Research to Examine Behavioral Responses to Automated Vehicles". The correction chapter and the book have been updated with the change. 